\title{
The Comparison of Functional Fitness and Self-esteem among Elderly Women Engaging Different Exercise Programs: Walking, Low Impact Aerobic, and Chi-kung 從事不同蓮動型態中、老年婦女功能性 體邅能狀況及自尊心之比較
}

\author{
Gladys Shuk-Fong LI Hsiu-Hua WANG Chen-Yu HUANG \\ National Chung Cheng University, TAIWAN
}

李淑芳王秀華黄飨銀 台灣國立中正大學

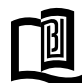

\begin{abstract}
Purposes: 1) Elderly females engaging different exercise programs (walking, low impact aerobic, chi-kung) and sedentary elderly women were compared on self-esteem and functional fitness; 2) The predictability of the 6 functional fitness variables to self-esteem was also tested. Methods: 256 elderly females (55-75 years old) were selected from each of the 3-exercised group (walking, low-impact aerobic, and chi-kung class) and sedentary group respectively. Measuring instruments included Functional Fitness Test and Rosenberg Self-Esteem Scale (RSES). One-way ANOVA was utilized to compare the three exercised-group of subjects on the overall self-esteem score (Rosenberg, 1965), and the multiple regression analysis was utilized to determine whether the 6 functional fitness predictors add to a linear function of self-esteem. Results: 'Flexibility' was found to be significant $(\mathrm{p}<.05)$ predictor of self-esteem. Self-esteem , 'BMI', 'FLEX', 'BAL', and 'AGIL' of the physically active elderly women were significantly $(\mathrm{p}<.05)$ better than the non-exercised women. Furthermore, Self-esteem , 'BMI', 'FLEX', 'BAL', 'MUSCU', and 'AGIL' scores of the elderly women of low impact aerobic exercised-group was significantly higher than those of the walking and Chi-kung group. However, no significant differences $(p>.05)$ were found among the three groups in the mean' CARDIO' scores. Conclusion: Elderly females engaging in low impact aerobic have higher self-esteem and better functional fitness. Furthermore, Flexibility is the most important predictor of self-esteem in elderly females.
\end{abstract}

Key words: aging, self-esteem, functional fitness

\section{摘 要}

目的：比較從事步行、低衝擊有氧、及氣功, 與久坐生活形態之中老年婦女, 其自尊值和功能性體適能之差異。同時評估六 項功能性體適能指標對於自尊值的預測能力。方法：以256位自願參與, 年齡介於55歲到77歲之中老年婦女為受測者, 其中 49 位為 久坐生活形態的中老年婦女，85位從事氣功；35位從事步行，以及87位從事低衝擊有氧運動。本研究之測量包括功能性體適能測 驗以及羅斯伯格自尊心之浿量。結果：一、功能性體適能中柔軟度為自尊程度的顯著 $(\mathrm{p}<.05)$ 預測用變項; 二、從事規律 運動的中老年婦女之自尊值、身體質量指數、柔軟度、平衡、及敏捷性顯著 $(\mathrm{p}<.05)$ 高於沒有從事規律運動的中老年婦女; 三、從事低衝擊有氧運動之中老年婦女的自尊程度和功能性體適能顯著 $(\mathrm{p}<.05)$ 高於從事步行、氣功的中老年婦女。結論： 從事低衝撃有氧運動的參與者有較高的自尊及較好的功能性體適能狀沉。除此之外, 柔軟度是「自尊」之重要預測用變項。

關鍵詞 : 老化、自尊、功能性體適能 


\section{壹、緒論}

\section{一、前言}

依據行政院主計處的統計，到了 2003 年65歲以上人口 佔總人口比例高達 $9.2 \%$, 顯示台灣早已成為高齡社會。防止 老化以及提高中、老年人之健康生活品質已成為重要的研究 課題。以往的研究曾經探討生理上功能, 以及動作能力的退 化是因為年齡和久坐的生活形態所造成 (Hopkins, Murrah, Hoeger, \& Rhodes, 1990; Sharkey, 1997; \& Shephard, 1997）。Sharkey（1997）提到年齡和活動對有氧體適能的影 響, 未從事規律活動的人其有氧體適能, 約每十年會退化8 $10 \%$; 而持續從事規律活動的人比不活動的人可以減少 一半的退化程度約每十年4 5\% ; 致力於接受體適能運動 訓練的人更可以降低退化的程度到每十年 $2.5 \%$ 。

身體活動、運動、和體適能訓纱對於老年人的益處, 在 一些前人的研究上已經被證實 (Berkman，1996; Hopkins 等, 1990 \& Ready等, 1996) 。不同型態的運動, 像是 步行、伸展運動、以及有氧訓練等對於老年人的好處, 都 在許多的研究中被驗證了 (Berkman, 1996; Ready等 \& Tseng, Marsh, Hamilton, Booth, 1996) 。

Ready等（1996）研究健走的量對於停經後婦女之有氧 適能、血脂濃度、與身體組成的效益, 結果發現身體的脂肪 百分比呈現有意義的降低。相對於控制組來説，從事每週3 至5次的步行活動, 並持續准行 24 週後, 實驗組攝氧量會增 加 $\circ$ Tseng, Marsh, Hamilton, Booth, (1996) 亦提出一些 針對老年人體適能研究指出 $45 \sim 50$ 歲和 $60 \sim 65$ 歲期間肌力會減 少 $22 \%$, 骨骼肌損失的速度會因為肌力訓練而減緩, 並且在 50歲以前就必須及早開始, 以作為預防的措施, 並且有氧運 動能夠預防慢性病和預防失能的發生, 而減少生病的機會並 降低死亡率, 進而提升了老年人的生活品質。

然而, 台灣國內針對從事不同運動方式的老年人, 有 關於其心理上的特徵以及功能性體適能差異的相關及比較 研究並不多, 很少針對老年人的研究, 尤其是有關於運動對 老年人有何好處的研究資料並不多, 台灣老年人在體適能測 量及評估工具和有效的體適能處方的發展上, 更是被忽略的 族群。比較從事規律運動和久坐生活形態年長婦女之功能性 體適能, 以及心裡狀沉方面的差異, 可以確認並獲得有意義 的證明, 年長的婦女族群應該從事哪些合適且容易實施的活 動, 並從中獲得最大之健康利益。此外, 亦可瞭解中老年婦 女功能性體適能狀態和心理健康之間是否有相關性存在。

最近台灣在運動及體適能程度關係的相關研究被一些 學者探討, Li, Chen, 與 Hsieh在1998年研究瑜珈對中年 婦女的健康體適能的影響, 發現瑜珈對柔軟度和肌耐力有益 處。Huang 在1994年的研究發現快速的走路運動能增加大
專生的健康體適能, 步行 1600 公尺對大專女生的心肺功能有 幫助, 而且能減少脂肪百分比。

自尊對解釋人類行為的重要性早已被接受及肯定 (Fox \& Corbin, 1989) 。因此, 解釋不同型態的規律運動與自 尊程度關係之差異性, 能使運動處方更為實際有效。研究者 曾經提出身體活動與心理健康具有顯著的相關性, 規律的運 動可以促進心理健康（Sonstroem \& Morgan, 1989; Van Andel \& Austin, 1984) 。 Sonstroem and Morgan (1989) 的研究顯示正向的情緒和長期的規律運動有關（p. 329）。 Ford等（1991）比較肌力訓練、塑身運動、和慢跑三種運 動, 對於自我知覺及精神集中效果的差異, 其研究結論為後 兩者對自我認同及精神集中具有正向的影響, 很多學者亦發 現體適能運動與部分的心理變項呈正相關。Chung (1993) 研究發現大專男生的健康體適能與自尊有正相關, 其研究結 論為大專男生的心肺耐力、肌力、及身體組成越高, 受試者 自尊值越高。

Liu（1998）研究大學生體適能和運動自覺之間的關 係, 結果發現其整體體適能指數 (Index of Overall Physical Fitness) 和運動自覺分數 (Sport-specific self-concept) 呈現正相關。然而, 台灣很少探討關於不同老年人運動族 群, 其心理變項與功能性體適能程度的比較研究, 藉由提供 可行有效的運動處方, 進一步分辨從事規律運動與不運動的 久坐生活形態老年人族群, 其功能性體適能程度及心理狀態 的差異性。再者, 藉由確定不同型態之規律運動對於體適能 狀態及心理素質的差異, 使得老年人之運動處方更為可行有 效, 並增強中老年人運動之服從效力; 最後, 藉由結合心理 健康素質及功能性體適能, 建立身心合一強而有力之連結關 係。

\section{二、研究目的}

本研究目的乃針對從事不同規律運動（體適能步行、低 衝擊有氧、及氣功）與未從事規律運動5 5 75歲中老年婦女 做自尊與功能性體適能 (身體組成、心肺耐力、柔軟度、肌 力/肌耐力、身體敏捷性、平衡感）作比較分析，同時亦評 估中老年婦女自尊量表和六項功能性體適能測驗之間的相關 性。

\section{武・方法}

\section{一、研究對象}

本研究共有256位自願參與之中老年婦女為受測者, 年 龄介於55歲到77歲之間, 其中 49 位為久坐生活形態者且未從 事規律運動的中老年婦女（N），其他207位為從事不同運動 型式之規律運動組, 分別有 85 位從事氣功課程 $(\mathrm{C})$ ； 35 位從事體適能步行 ( W ) , 以及87位從事低衝擊有氧運動 (A)。 
本研究以運動頻率來界定規律運動和久坐生活型態中 老年婦女的定義。不管是從事氣功、步行、或低衝擊的有氧 運動，每週進行3小時以上至少持續一年定義為運動組。在 過去的一年中未從事規律運動之久坐生活形態之中老年婦女 則為本研究的控制組。實驗進行之前, 研究者須事先告知所 有參與者本研究之本質、目的、和參與研究的危險性, 以取 得受試者參與意願，並且皆須填寫疾病調查表、身體活動問 卷、及受試者同意書。

\section{二、测量工具}

（一）本研究之功能性體適測驗項目包含身體質量指數、柔 軟度、心肺指數、平衡、肌力、敏捷性等六項（Rikli \& Jones ，2001），其乃利用Rikli and Jones (2001) 之六個功能性體適能項目方法檢測：1.身體質 量指數：身體組成； 2. 坐姿體前彎測驗：柔軟度 ; $3.1 / 2$ 英里步行 測 驗：心肺耐力; 4 . 單腳站立測 驗 : 平衡; 5 .坐姿到站立測驗 : 肌力及肌耐力; 6 . 椅 上敏捷度測驗：身體敏捷性

（二）本研究之自尊值以羅斯伯格自尊量表（Rosenberg Self-Esteem Scale，Rosenberg，1965）所測量而 得之自尊程度為本研究自尊值定義。

\section{三、統計分析}

本研究問卷及檢測所得之數據資料, 利用Statistical Package for Social Sciences 10.0 (SPSS) 系統進行統計 分析。主要的統計方法有：（一) 描述統計；二獨立樣本 $\mathrm{T}$ 考驗; (三) 單因子變異數分析; (四) 皮爾遜相關 ; (五) 多元回歸分析。

\section{參、結果}

本研究探討從事不同型態規律運動中老年婦女（體適 能步行、低衝擊有氧及氣功）與未從事規律運動之中老年婦 女; 依變項分別為六項功能性體適能指標（身體質量指數、 柔軟度、心肺指數、平衡、肌力、敏捷性）及自尊值。其分 析結果如下所示：

\section{一 有無從事規律運動中老年㖊女自尊值及功能性體 通能之比較}

根據表一獨立樣本 $\mathrm{T}$ 考驗分析結果顯示, 身 體質量指數之 $\mathrm{t}=2.28(\mathrm{p}<.05)$, 柔軟度之 $\mathrm{t}=-3.70$ $(\mathrm{p}<.01)$ ，平衡之 $\mathrm{t}=-3.07(\mathrm{p}<.01)$ ，敏捷性之 $\mathrm{t}=2.00(\mathrm{p}<.05)$, 自尊值之 $\mathrm{t}=-2.41(\mathrm{p}<.05)$, 心肺耐力之 $\mathrm{t}=-1.31(\mathrm{p}>.05)$, 肌力之 $\mathrm{t}=-1.85$ （p>.05），代表從事規律運動之中老年婦女與未從事規律運 動之中老年婦女在身體質量指數、柔軟度、平衡、敏捷性、 及自尊有顯著 $(p<.01)$ 差異, 並且對照圖一的各組平均值 後, 可知從事規律運動之中老年婦女有較低的身體質量指 數, 較好的柔軟度與平衡能力、敏捷性, 以及較高的功能 性總體適能。在心理素質方面, 從事規律運動之中老年婦 女的自尊程度顯著 $(\mathrm{p}<.05)$ 高於沒有從事規律運動之中 老年婦女, 但是在心肺耐力與肌力方面未達統計上的顯著 (p>.05) 差異（參見表一）。

\section{表一 有無規律運動其功能性體道能與自尊平均值之考驗}

\begin{tabular}{|c|c|c|c|c|c|}
\hline 變 項 & 有/無運動 & 平均數 & 標準差 & $\mathrm{t}$ 值 & 顯著性（雙尾） \\
\hline 體質量指數 & $\begin{array}{l}\text { 有運動 }=207 \\
\text { 無運動 }=49\end{array}$ & $\begin{array}{l}23.75 \\
25.05 \\
\end{array}$ & $\begin{array}{r}3.00 \\
3.75 \\
\end{array}$ & 2.275 & $.026^{*}$ \\
\hline $\begin{array}{l}\text { 柔軟度 } \\
\text { (公分) }\end{array}$ & $\begin{array}{l}\text { 有運動=207 } \\
\text { 無運動=49 }\end{array}$ & $\begin{array}{r}10.70 \\
6.00 \\
\end{array}$ & $\begin{array}{r}8.25 \\
6.87 \\
\end{array}$ & -3.704 & $.000^{*}$ \\
\hline 心肺功能 & $\begin{array}{l}\text { 有運動=207 } \\
\text { 無運動= } 49\end{array}$ & $\begin{array}{r}579.80 \\
557.73 \\
\end{array}$ & $\begin{array}{l}103.27 \\
117.05 \\
\end{array}$ & -1.310 & .191 \\
\hline $\begin{array}{l}\text { 平衡性 } \\
\text { (秒) }\end{array}$ & $\begin{array}{l}\text { 有運動=207 } \\
\text { 無運動 }=49\end{array}$ & $\begin{array}{l}26.24 \\
22.01 \\
\end{array}$ & $\begin{array}{l}7.14 \\
9.00 \\
\end{array}$ & -3.067 & $.003^{*}$ \\
\hline $\begin{array}{l}\text { 肌力 } \\
\text { (次) }\end{array}$ & $\begin{array}{l}\text { 有運動=207 } \\
\text { 無運動=49 }\end{array}$ & $\begin{array}{l}23.56 \\
21.96 \\
\end{array}$ & $\begin{array}{l}5.61 \\
4.80 \\
\end{array}$ & -1.849 & .066 \\
\hline $\begin{array}{l}\text { 敏捷 } \\
\text { (秒) }\end{array}$ & $\begin{array}{l}\text { 有運動=207 } \\
\text { 無運動=49 }\end{array}$ & $\begin{array}{l}242.30 \\
277.08 \\
\end{array}$ & $\begin{array}{r}60.24 \\
118.32 \\
\end{array}$ & 1.997 & $.004^{*}$ \\
\hline 自尊心 & $\begin{array}{l}\text { 有運動=207 } \\
\text { 無運動=49 }\end{array}$ & $\begin{array}{l}36.98 \\
35.12 \\
\end{array}$ & $\begin{array}{l}4.95 \\
4.28 \\
\end{array}$ & -2.413 & $.017 *$ \\
\hline
\end{tabular}

$* \mathrm{p}<.05$ 


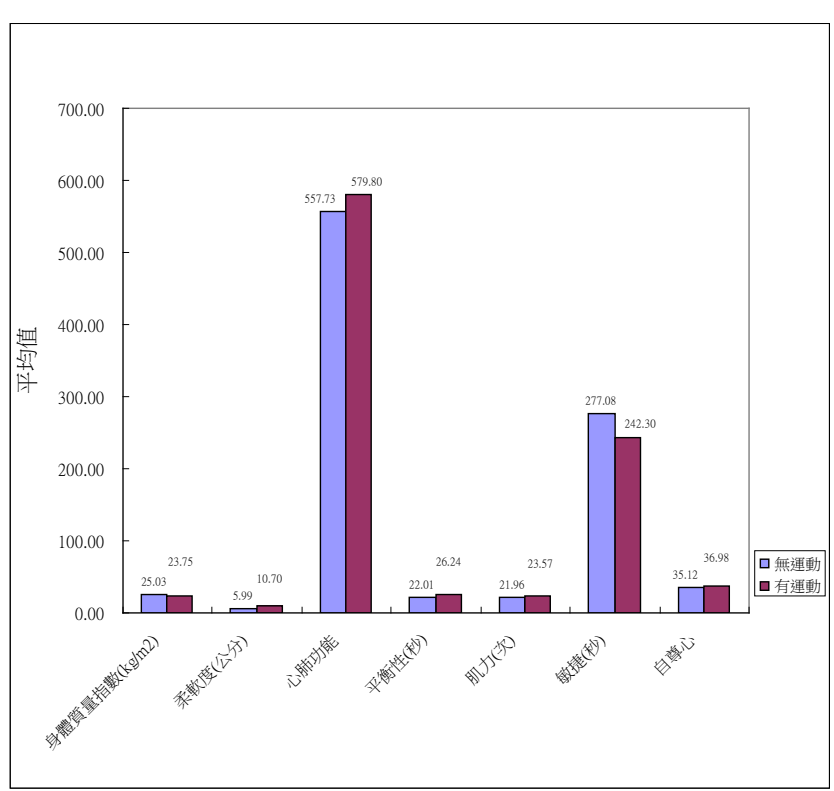

圖一 有無運動分組之平均值長條圖之比較

\section{二、 從事不同型態规律運動中老年㖊女的功能性體 通能與自尊的差異性根握單因子變}

異數分析結果顯示，從事不同規律運動的中年婦女， 其在身體質量指數 $(F(3,255=4.47, \quad \mathrm{p}<.01))$ 、柔軟 度 $(\mathrm{F}(3,255=7.71, \mathrm{p}<.01))$ 、平衡 $(\mathrm{F}(3,255=7.06$, $\mathrm{p}<.01))$ 、肌力 $(\mathrm{F}(3,255=7.77, \mathrm{p}<.01))$ 、敏捷性 (F $(3,255=6.76, \quad \mathrm{p}<.01))$ 、及自尊方面（F（3,255=5.26, $\mathrm{p}<$.01））都達到統計上的顯著差異水準。代表從事體適 能步行、低衝擊有氧及氣功的中老年婦女，受試者彼此之間 的體能狀態及自尊方面有明顯的不同。再進一步作成對樣本 檢定後，並對照圖二各組之平均值發現（見表二，步行、氣 功、低衝撃有氧分別以 $W \cdot C 、 A$ 為代表號），在身體質量 指數及自尊項目中, 從事低衝擊有氧運動的效果比氣功好 $(A>C)$; 在柔軟度、平衡性、肌力、敏捷項目中, 從事低衝 擊有氧運動的效果比從事氣功、步行運動好, 而且從事氣功 與步行運動的效果無差異 $(\mathrm{A}>\mathrm{W}=\mathrm{C})$; 在心肺功能項目則 無顯著差異, (參見表二)。

\section{表二 不同型態規律運動功能性體適能與自尊值之差異比較}

\begin{tabular}{|c|c|c|c|c|}
\hline 依變項 & 不同型態運動組別平均數(標準差) & 配對 & 顯著性（雙尾） & 比較結果 \\
\hline 身體質量指數 & $\begin{array}{l}\text { 氣功 }(\mathbf{C}): 24.30(2.84) \\
\text { 步行 }(W): 23.28(3.54) \\
\text { 低衝擊有氧(A):23.40 (2.87) }\end{array}$ & $\begin{array}{l}\text { 步行 \& 氣功 } \\
\text { 步行 \& 低衝擊有氧 } \\
\text { 低衝擊有氧 \& 氣功 }\end{array}$ & $\begin{array}{l}.135 \\
.940 \\
.026^{*} \\
\end{array}$ & $\mathrm{~A}>\mathrm{C}$ \\
\hline $\begin{array}{l}\text { 柔軟度 } \\
\text { (公分) }\end{array}$ & $\begin{array}{l}\text { 氣功 }(\mathrm{C}): 9.03(8.17) \\
\text { 步行 }(\mathrm{W}): 9.39(6.17) \\
\text { 低衝擊有氧(A):9.39(8.17) }\end{array}$ & $\begin{array}{l}\text { 步行 \& 氣功 } \\
\text { 步行 \& 低衝擊有氧 } \\
\text { 低衝擊有氧 \&氣功 }\end{array}$ & $\begin{array}{l}.797 \\
.017 * \\
.004 * \\
\end{array}$ & $\mathrm{~A}>\mathrm{W}=\mathrm{C}$ \\
\hline 心肺功能 & $\begin{array}{l}\text { 氣功 }(\mathrm{C}): 567.45(74.15) \\
\text { 步行 }(\mathrm{W}): 575.51(128.83) \\
\text { 低衝擊有氧(A):593.60 (115.17) }\end{array}$ & $\begin{array}{l}\text { 步行 \& 氣功 } \\
\text { 步行 \& 低衝擊有氧 } \\
\text { 低衝擊有氧 \& 氣功 }\end{array}$ & $\begin{array}{l}.730 \\
.428 \\
.059 \\
\end{array}$ & 無差異 \\
\hline $\begin{array}{l}\text { 平衡性 } \\
\text { (秒) }\end{array}$ & $\begin{array}{l}\text { 氣功 }(\mathrm{C}): 25.59(7.55) \\
\text { 步行 }(\mathrm{W}): 23.74(9.26) \\
\text { 低衝擊有氧(A):27.87 (5.20) }\end{array}$ & $\begin{array}{l}\text { 步行 \& 氣功 } \\
\text { 步行 \& 低衝擊有氧 } \\
\text { 低衝擊有氧 \& 氣功 }\end{array}$ & $\begin{array}{l}.301 \\
.017 * \\
.022 * \\
\end{array}$ & $\mathrm{~A}>\mathrm{W}=\mathrm{C}$ \\
\hline $\begin{array}{l}\text { 肌力 } \\
\text { (次) }\end{array}$ & $\begin{array}{l}\text { 氣功 }(\mathrm{C}): 22.13(4.96) \\
\text { 步行 }(\mathrm{W}): 22.20(6.92) \\
\text { 低衝擊有氧(A):25.52 (5.09) }\end{array}$ & $\begin{array}{l}\text { 步行 \& 氣功 } \\
\text { 步行 \& 低衝擊有氧 } \\
\text { 低衝擊有氧 \& 氣功 }\end{array}$ & $\begin{array}{l}.956 \\
.014^{*} \\
.000^{*} \\
\end{array}$ & $\mathrm{~A}>\mathrm{W}=\mathrm{C}$ \\
\hline $\begin{array}{l}\text { 敏捷 } \\
\text { (秒) }\end{array}$ & $\begin{array}{l}\text { 氣功 }(\mathrm{C}): 260.84(72.44) \\
\text { 步行 }(\mathrm{W}): 247.69(53.39) \\
\text { 低衝擊有氧 }(\mathrm{A}): 222.02(40.90)\end{array}$ & $\begin{array}{l}\text { 步行 \& 氣功 } \\
\text { 步行 \& 低衝擊有氧 } \\
\text { 低衝擊有氧 \&氣功 }\end{array}$ & $\begin{array}{l}.000 \\
.275 \\
.014^{*} \\
.000^{*}\end{array}$ & $\mathrm{~A}>\mathrm{W}=\mathrm{C}$ \\
\hline 自尊心 & $\begin{array}{l}\text { 氣功 }(\mathrm{C}): 35.97(4.48) \\
\text { 步行 }(\mathrm{W}): 36.49(4.90) \\
\text { 低衝擊有氧(A):38.25 (5.18) }\end{array}$ & $\begin{array}{l}\text { 步行 \& 氣功 } \\
\text { 步行 \& 低衝擊有氧 } \\
\text { 低衝擊有氧 \& 氣功 }\end{array}$ & $\begin{array}{l}.524 \\
.089 \\
.002 *\end{array}$ & $\mathrm{~A}>\mathrm{C}$ \\
\hline
\end{tabular}

$* \mathrm{p}<.05$ 註:步行、氣功、低衝擊有氧分別以W、 $\mathrm{C} 、 \mathrm{~A}$ 為代表號。 


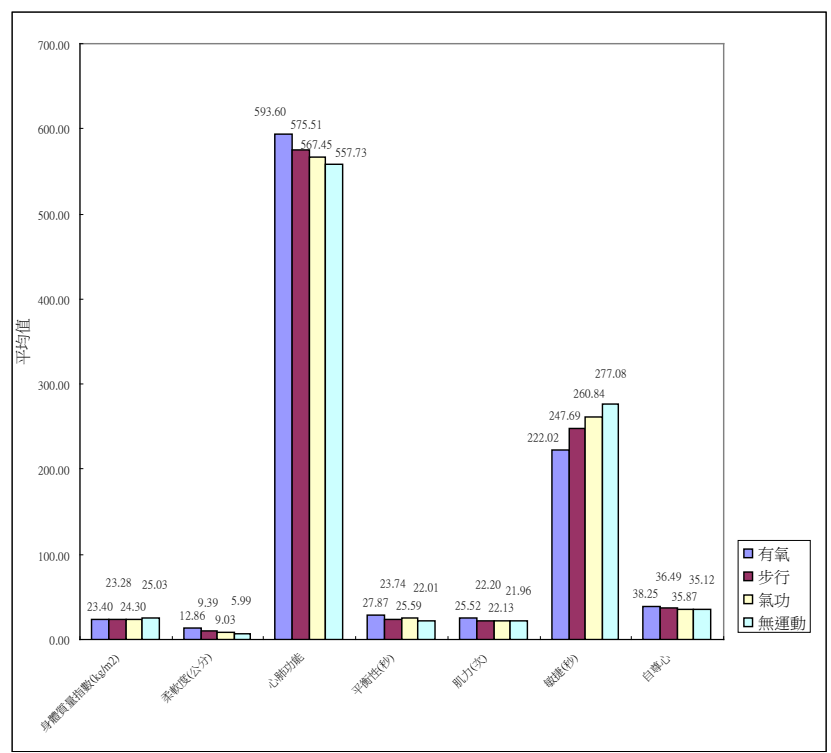

圖二 不同運動型態與無運動組各組平均值長條圖

\section{三、功能性體適能項目是否可成為自尊之預測變項}

本分析採用逐步回歸分析法進行多元回歸分析, 發現 身體質量指數 $(\mathrm{R}=-.15, \mathrm{p}<.01)$ 及敏捷性 $(\mathrm{R}=-.15$, $\mathrm{p}<.01 ）$ 分別與自尊值呈現負相關。柔軟度 $(\mathrm{R}=.29, \mathrm{p}<$ $.01)$ 及肌力 $(\mathrm{R}=.14, \mathrm{p}<.05)$ 分別與自尊值呈現正相 關。多元相關係數 $\mathrm{R}=.29, \quad \mathrm{R}^{2}=.09$, 標準誤為 4.68, 分析 結果只有「柔軟度」能成為「自尊」之預測用變項。其原始 分數的回歸方程式可寫成： $\mathrm{Y}=0.17$ 柔軟度 +34.92 , 其餘 功能性體適能變項無法有效預測自尊值。

\section{肆、討論}

本研究發現從事規律運動之中老年婦女在自尊及功能 性體適能狀沉方面均較優於未從事規律運動之中老年婦女； 而且, 從事低衝擊有氧運動的參與者比從事氣功、步行的參 與者, 有較好的柔軟度、肌力、敏捷性和平衡能力。以上的 結果與過去的研究有吻合之處。惟許多學者分別研究不同 型態的運動, 像是步行、氣功、以及有氧訓練等對於中、 老年人身體與心理功能的好處（Berkman， 1996; Ready等， 1996; \& Tseng, Marsh, Hamilton, Booth, 1996) , 鮮 少同時分析不同運動介入對於身、心理效益之比較。學者探 討規律步行運動對於各受試團體之效益, 發現規律健走對 於停經後婦女之身體脂肪百分比呈現降低之效果 (Ready 等, 1996）; 能改善糖尿病病人之BMI, 脂肪代謝與血壓 指數（Fritz，Wandell， Aberg，與 Engfeldt，2005）; 使 療養院病人的功能性體適能與BMI指數都獲得改善 (Tully, Cupples, Chan, McGlade, 與Young, 2005)。在有氧運動 方面, 從事家居中等強度之有氧運動, 能增淮腰椎盤脱出病 人之心肺功能與下背柔軟度 (Sculco， Paup，Hamm，Fern- hall與 Sculco，2004），改善血脂肪而導致身體肥胖之降低 （Katzmarzyk等，2001），及增進無律性運動中老年人之體適 能 (張蓓貞、吳麗貞、彭淑美, 2003)。在太極氣功方面, Li，Fisher與McAuley (2002) 發現65歲以上從事太極學員之 自覺身體功能有顯著進步, 雖然個別學員的進步程度表現有 較大的差異。以上的研究結果與本研究之結果相符合, 都證 實步行、有氧運動及氣功均能提昇中、老年人之自尊與功能 性體適能。

而在自尊方面, 本研究發現從事規律運動中、老年婦女 的自尊較高之結果與很多研究之結果相符合; Levy與Ebbeck （2005）支持中年婦女運動與自尊關係之存在；Sonstroem 與 Morgan（1989）的研究顯示長期的規律運動與正向的情緒有 相關性。Taylor與Fox (2005) 發現10週之運動介入能提升 40-70歲安養院中、老人身體之自我價值感。另外, Elavsky與 McAuley (2005) 發現愈常參與身體活動之停經婦女, 其自 尊、身體自我價值感, 與健康生活品質上都比不規律性進行 身體活之之停經婦女為高。而從事低衝擊有氧運動之中老年 婦女的自尊比從事體適能步行、與氣功的中老年婦女為佳之 結果卻沒有直接類似之研究可比照。

然而功能性體適能項目是否可成為自尊之預測變項的研 究結果發現自尊與身體質量指數（BMI）及敏捷性分別值呈 現負相關，與柔軟度成高度正相關，而分別與自尊值呈現正 相關此結果和Chung (1993) 的研究結果不同, 其研究結果 指出美國大學男學生的心肺耐力、肌力、和身體組成指數越 好時其自尊值越高, 這可能是因為年齡與性別上的差異, 以 及東西方文化上對於自我價值觀念上的不同所致。

本研究從上述結果, 得到以下幾點結論：(一) 從事 規律運動中老年婦女的自尊心比未從事規律運動的年長婦女 高, 且低衝擊有氧運動者的自尊心, 比從事氣功與步行活動 的參與者高。（二）從事規律身體活動的中老年婦女比未從 事規律運動的中老年婦女有較好的身體質量指數、柔軟度、 平衡能力、和敏捷性。(三) 中老年婦女從事低衝擊有氧運 動比氣功, 及步行參與者的柔軟度、肌力、敏捷性和平衡能 力更有幫助。(四) 中老年婦女的柔軟度愈好, BMI愈低, 敏捷性愈好, 其自尊心愈高。因此, 本研究結果可以提供作 為中老年婦女設計運動處方時的參考與建議。 


\section{引用文獻}

張蓓貞、吳麗貞、彭淑美 （2003）。無規律性運動中老年 人運動介入成效評估研究。台灣衛誌, 22(1)，1-9

Berkman, L.(Feb 28, 1996, New York Times). Baltimore Longitudinal Study on Aging.

Chung, P. K. (1993). The relationship of health-related physical fitness and self-esteem in male college students. Unpublished doctoral dissertation, Springfield College, Springfield, MA.

Elavsky, S. \& Mcauley, E. (2004). Physcial activity, symptoms, esteem, and life satisfaction during menopause. Maturitas, 52(3-4), 374-385.

Ford, H. T., Puckett, J. R., Reeve, T. G., \& Lafavi, R. G. (1991). Effects of selected physical activities on global selfconcept and body-cathexis scores. Psychological Reports, 68, 1339-1343.

Fox, K. R., \& Corbin, C. B.(1989). The physical validation. Journal of sport and Exercise Psychology, 11, 408-430.

Fritz, T., Wandell, P., Aberg, H., \& Engfeldt, P. (2005). Diabetes Research and Clinical Practice. Article in press.

Huang, P. P. (1994). Effects of walking on health relatedfitness. CTUSF. Proceeding of conference on physical education and sport 1994. Chia-yi, Taiwan: National Chung Cheng University.

Hopkins, D. R., Murrah, B., Hoeger, W., \& Rhodes, R. C. (1990). Effect of low-impact aerobic dance on the functional fitness of elderly women. Gerontological Society of America, 30(2), 189-192.

Katzmarzyk, P. T., Leon, A. S., Rankinen, T., Gagnon, J., Skinner, J. S., Wilmore, J. H., Rao, D. C., \& Bouchard, C. (2001). Changes in Blood Lipids Consequent to Aerobic Exercise Training Related to Changes in Body Fatness and Aerobic Fitness. Metabolism, 50(7), 841-848.
Levy, S. S., \& Ebbeck, V. (2005). The exercise and selfesteem model in adult women: the inclusion of physical acceptance. Psychology of Sport and Exercise, 6, 571-584.

Li, F.H., Fisher K.H, Harmer, P., \& McAuley, E. (2002). Delineating the impact of Tai Chi training on physical function among the elderly. American Journal of Preventive Medicine, 23(2), 92-97.

Li, M. Y., Chen, W. N., \& Hsieh, C. C. (1998). Effect of Hatha yoga asana in women on health related physical fitness. CTUSF Proceeding of conference on physical education and sport 1994. Chia-yi, Taiwan: National Chung Cheng University.

Liu, C. H. (1998). Study of the relationships between collegiate students' physical fitness and sportspecificself-concept. CTUSF Proceeding of conference on physical education and sport 1994. Chia-yi, Taiwan: National Chung Cheng University.

Ready, A., Naimark, B., Ducas, J., Sawatzky, J., Boreskie, S., Drinkwater, D., \& Oosterveen, S. (1996). Influence of walking volume on health benefits in women post-menopause. Medicine and Science in Sports and Exercise, 44, 1097-1105.

Rikli, R. E., \& Jones, C. J. (2001). Seniors fitness test manual. Champaign, IL: Human Kinetics.

Rosenberg, M. (1965). Society and the adolescent selfimage. Middletown, CT: Wesleyan University Press.

Sculco, A. D., Paup, D. C., hamm, L. F., Fernhall, B. \& Sculco, J. (2004). The Spine Journal, 4(5), S92-S93.

Sharkey, B.J. (1997). Fitness and Health. Champaign, IL: Human Kinetics.

Shephard, R. J. (1997). Aging, physical activity and health. Champaign, IL: Human Kinetics.

Sonstroem, R, J., \& Morgan, W. P. (1989). Exercise and self-esteem: Rationale and model. Medicine and Science in Sports and Exercise, 21(3), 329-337. 
Taylor, A.H. \& Fox, K.R. (2005). Health Psychology, 24 (1), $11-21$.

Tseng B. S., Marsh D. R., Hamilton M. T., \& Booth F. W. (1995). Journal of Gerontology, 50A, 113-119.

Tully, M. A., Cupples, M. E., Chan, W. S., McGlade, K., \& Young, I. S. (2004). Preventive Medicine, 41(2), 622-628.

Van Andel, G. E., \& Austin, D. R. (1984). Physical fitness and mental health: A review of the literature. Adapted Physical Activity Quarterly, (1), 207-220.

Van Norman, K. A. (1995). Exercise programming for older adults. Champaign, IL: Human Kinetics.

\section{聯絡人：}

李淑芳

通訊地址：621嘉義縣民雄鄉大學路168號 國立中正大學運休所

電話：0931780540

傳真：（05）2721070

Email : admsfl@ccu.edu.tw

王秀華

通訊地址：621嘉義縣民雄鄉大學路 168 號國立中正大學運休所

電話：0952422818

傳真：（05）2721070

Email : grcsww@ccu.edu.tw 